\title{
CONSTRUCTION CLAIMS IN THE UNITED ARAB EMIRATES: TYPES, CAUSES, AND FREQUENCY
}

\author{
Essam Zaneldin \\ Department of Civil \& Environmental Engineering, United Arab Emirates University, PO Box 17555, \\ Al-Ain, United Arab Emirates
}

\begin{abstract}
The United Arab Emirates (UAE) government is investing millions of dollars every year in new facilities to improve the infrastructure of the country. Infrastructure development has been phenomenal in view of the relatively brief period since the country's establishment. In view of this, the construction industry is considered the largest single industry in UAE. Yet, it is also very complex and the most fragmented industry as it involves multidisciplinary participants and several stake holders. Today, construction projects are the subject of more claims than in any other time in history. Claims appear to hinder the completion of construction and cause delays in delivering projects. This research presents the results of a pilot study of the types, causes, and frequency of construction claims in the emirates of Dubai and Abu Dhabi in UAE using a questionnaire survey that was conducted in the two emirates. The data received from the survey respondents is analyzed and recommendations to prevent/reduce claims in construction projects are then presented. It is expected that the findings of this research will help construction firms avoid the main causes of claims and, accordingly, minimize delays and cost overruns in construction projects.
\end{abstract}

Keywords: Delays, Claims, Construction industry, Cost overruns, Survey.

\section{INTRODUCTION}

Construction claims are considered by many project participants to be one of the most disruptive and unpleasant events of a project (Ho and Liu 2004). Today, construction projects are the subject of more claims than in any other time in history. The high competition has forced contractors to bid projects with minimum profits in order to stay in business. In addition to their multiparty nature, projects are becoming more complex and risky. This has placed an added burden on contractors to construct increasingly sophisticated and risky projects with less resources and profits. Under these circumstances, it is not surprising that the number of claims within the construction industry continues to increase (Ho and Liu 2004). In the following subsections, an outline of the construction industry in United Arab Emirates is first presented followed by a brief discussion on the types and causes of claims in construction projects.

\section{The Construction Industry in the United Arab Emirates}

Infrastructure development in the United Arab Emirates at federal and local levels has been phenomenal in view of the relatively short period since the establishment of the country. Modern cities have risen from the barren desert, connected by a vast network of first-class roads and linked to the outside world by modern airports and ports. Houses, schools, hospitals, shopping centers, telecommunications, electricity and water, luxury hotels and recreational facilities have all been provided in a remarkably short space of time. The current boom in the construction industry is the direct result 
of a high return on investment. This makes it the second largest sector after oil and gas. With plans to develop Dubai and Abu Dhabi as the major tourism centers and regional business and manufacturing bases, this growth is set to continue. Besides the freehold residential and commercial projects, several hotels and a number of large shopping malls are currently being constructed.

The construction industry is also the most fragmented industry. Unlike the manufacturing industries, the construction pie is shared by many contractors and subcontractors. Considering the giant size of the industry, it is hardly surprising that there are also a considerable number of claims. The real wonder is that there are so few rather than so many. Construction claims in UAE, normally seen in almost every construction project, are direct results of the ongoing growth in the construction industry in the country and in Dubai and Abu Dhabi Emirates, in particular.

\section{Construction claims}

In very simple terms, a claim can be defined as a request for compensation for damages incurred by any party to a contract (Semple et al. 1994). In the construction industry, claims are common and can happen as a result of several reasons that can contribute to delaying a project and/or increasing its costs (Gulezian and Samelian 2003 and Kartam 1999). Claims for additional costs or for time extensions occur during the course of construction. To enhance the chances of success, contractors must understand the main causes of claims and, when submitting a claim, provide enough information and present sufficient documentation. Project owners need also to follow an overall comprehensive step-by-step procedure for tracking and managing the claims submitted by contractors (Abdul-Malak et al. 2002, Singh and Sakamoto 2001, and Scott 1997).

Once a claim has been presented, the owner and contractor can come to an agreement concerning the claim and, thereby, create a change order or a modification, or they may disagree and create a construction contract dispute. Resolving and settling claims can take place through negotiation, mediation, arbitration, or litigation (Ren et al. 2003). However, analyzing the various causes that contribute to a project's delay is an important task to resolving it (Janney et al.1996). Determining the impact, timing, and the contributing effect of each of those causes to the overall delay should assist in helping the parties settle the delay without litigation (Vidogah and Ndekugri 1997). Generally, litigation required a long period of time and significantly higher legal costs, as compared to the other techniques mentioned above. Even though construction disputes are frequent and their resolution is difficult, many times legal advice is not sought because it is not available or because it is expensive. Project participants are becoming more aware of the delays and high costs and risks associated with claims. Thus, the construction industry needs to determine the main causes of claims and, accordingly, develop techniques to prevent or reduce claims.

Several attempts were made in the literature to study construction claims and determine their main causes in an attempt to avoid claims or at least reduce them. Scott (1997) conducted a survey to investigate the mechanisms that are being adopted to prepare and evaluate delay claims in United Kingdom. Hartman and Snelgrove (1996) evaluated the effectiveness of written contract language to communicate risk apportionment between contracting parties. Al-Khalil and Al-Ghafly (1999) determined the most important causes of delay claims in public utility projects in Saudi Arabia based on the frequency and severity of these causes. Chester and Hendrickson (2005) presented a case study of a project with seven different 
mismanagement scenarios. The damages that result from the problem were then presented with possible preventative steps to minimize these damages.

This research presents the results of a pilot study of the types, causes, and frequency of construction claims in the emirates of Dubai and Abu Dhabi in UAE using a questionnaire survey that was conducted in the two emirates. The data received from the survey respondents is analyzed and recommendations to prevent/reduce claims in construction projects are then presented.

\section{SCOPE OF STUDY}

A questionnaire survey was designed considering input from a number of consultants and contractors in Dubai and Abu Dhabi Emirates in UAE. The survey was mailed to more than one hundred firms in Dubai and Abu Dhabi Emirates. The questionnaire was organized into five main sections: 1) about the firm; 2) types of claims; 3) causes of claims; 4) settlement of claims, and 5) recommendations to avoid/reduce claims. Responses were received from 56 leading firms (22 contractors and 34 design offices and consultants) who have participated in a wide variety of small to large-size projects. The first section elicited general information about the participating firms, including specialty, services, and size of construction projects. Analysis of the responses received shows the profile of respondents as illustrated in Fig. 1. As can be depicted from the figure, 32\% of the participating firms are small size firms with 10 employees or less while 36\% of the respondents are firms with 20 to 100 employees. Large-size firms represent 32\% with more than 100 employees. The responding firms are engaged in a wide spectrum of project types and sizes. A Detailed analysis of the responses received from the survey is shown in the following section.

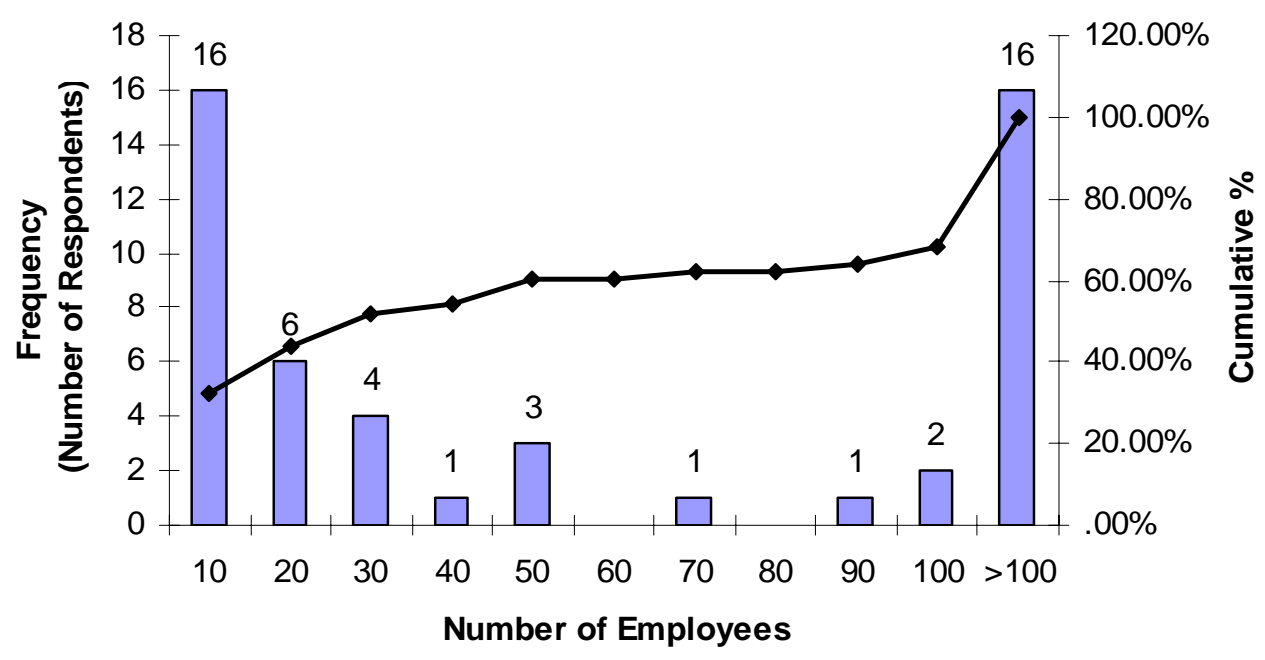

Fig. 1: Frequency of claims 


\section{DATA ANALYSIS}

Responses from 56 consultants and contractors to the questionnaire survey were analyzed in this section. Fig. 2 shows the percentage of claims associated with each type of projects, as repoted by the survey respondents. It can be depicted form the figure that the majority of claims exist in road and building projects, representing $65.33 \%$ of the total number of claims in all projects. Number of claims associated with power-plant projects was found to be the minimum with $3.23 \%$ only.

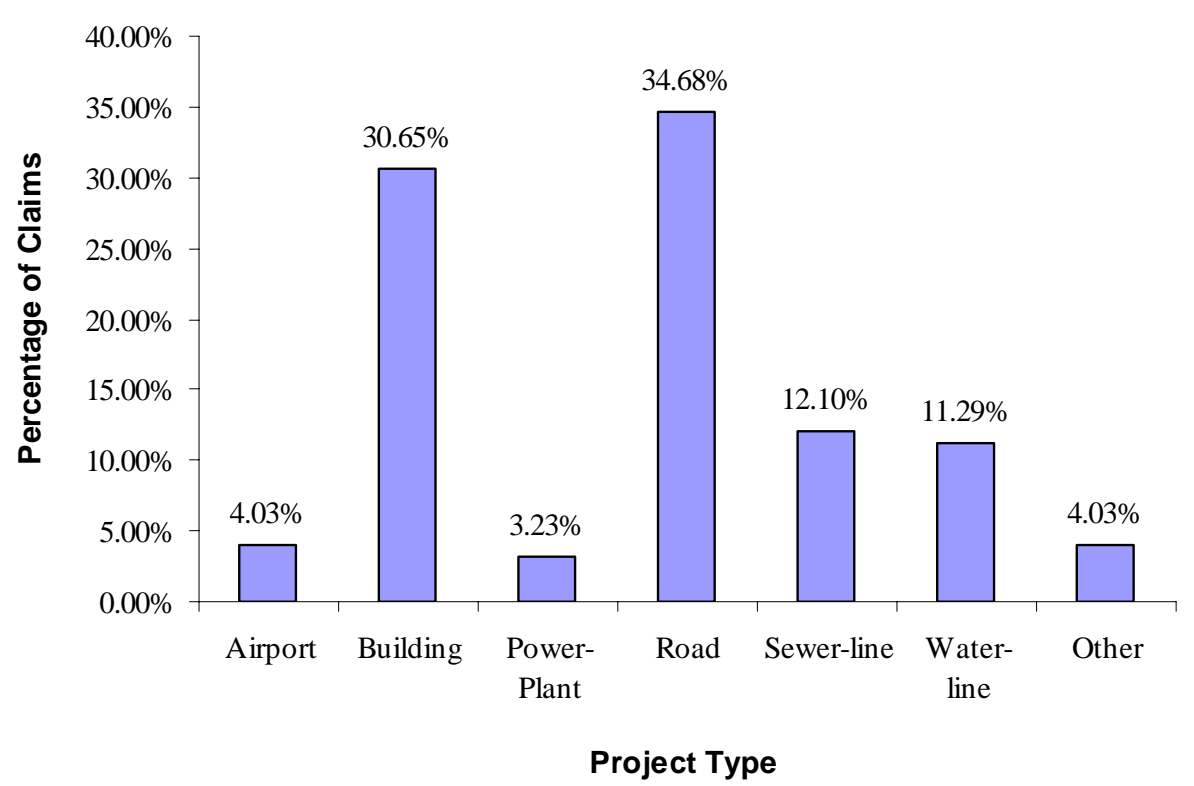

Fig. 2: Percentages of claims associated with each type of projects

The data of the responses were analyzed to provide an idea about the types, causes, and frequency of claims in Dubai and Abu Dhabi Emirates. A detailed discussion of the analysis is shown in the following subsections.

\section{Types of claims and their frequency}

The second section of the survey focused on the types of construction claims. In this section, a table was provided with eight possible types of claims. Firms were asked to choose one of five possible options for the frequency of each type of claims: never, rare, average, frequent, and very frequent. A weight in a scale from 0 to 4 was given for each of the five frequencies with a weight of 0 for "never, 1 for "rare", 2 for "average", 3 for "frequent" and 4 for "very frequent". The frequencies for each type of claims received from the survey respondents are listed in Table 1. Responses for the frequency of the "Changes" type of claims, for example, indicate that 2 firms responded as "never", 7 responded as "rare", 19 responded as "average", 18 responded as "frequent", and 10 responded as "very frequent". Data of Table 1 were analyzed and a "Weighted Average" was calculated for each type of claims as follows (see Table 2): 
Weighted Average $=\sum W_{i} x X_{i} / N$

Where:

$i \quad$ is the number of options (from 1 for "never" to 5 for "very frequent")

$W_{i} \quad$ is the weight assigned to the $i^{\text {th }}$ option;

$X_{i} \quad$ is the number of respondents who selected the $i^{\text {th }}$ option; and

$N \quad$ is the total number of respondents (56 in this study).

Table 1: Frequencies of each type of claims

\begin{tabular}{|c|c|c|c|c|c|c|}
\hline Types of Claims & $\begin{array}{c}\text { No } \\
\text { Response }\end{array}$ & Never & Rare & Average & Frequent & $\begin{array}{c}\text { Very } \\
\text { Frequent }\end{array}$ \\
\hline Contract Ambiguity Claims & 6 & 12 & 21 & 12 & 5 & 0 \\
\hline Delay claims & 2 & 4 & 12 & 17 & 18 & 3 \\
\hline Acceleration Claims & 4 & 12 & 17 & 12 & 7 & 4 \\
\hline Changes Claims & 0 & 2 & 7 & 19 & 18 & 10 \\
\hline Extra-Work Claims & 1 & 2 & 8 & 15 & 20 & 10 \\
\hline Different Site Conditions Claims & 0 & 9 & 20 & 20 & 6 & 1 \\
\hline Damage Claims & 4 & 16 & 17 & 12 & 5 & 2 \\
\hline Non-Performance Claims & 2 & 9 & 21 & 11 & 9 & 4 \\
\hline
\end{tabular}

For example, the weighted average for the "Changes" type of claims $=(0 * 2+1 * 7+$ $2 * 19+3 * 18+4 * 10) / 56=2.48$. An "Importance Index" percentage was then calculated for each type of claims as follows (see Table 2):

Importance Index $=$ Weighted Average $* 100 / 4$

For example, the importance index for the "Changes" type of claims $=(2.48 * 100) / 4=$ $62 \%$. The results of this analysis indicate that "Changes" claims are the most frequent type of claims. This type of claims was ranked first with an importance index of $62 \%$. "Extra-Work" claims were ranked second with an importance index of $61.5 \%$ while "Contract Ambiguity" claims were ranked last with an importance index of 26.8\%. The ranks of all types of claims are listed in the last column of Table 2.

Table 2: Ranking of the types of claims

\begin{tabular}{lccc}
\hline Types of Claims & Weighted Average & Importance Index (\%) & Rank \\
\hline Changes Claims & 2.48 & $62.0 \%$ & 1 \\
Extra-Work Claims & 2.46 & $61.5 \%$ & 2 \\
Delay Claims & 2.00 & $50.0 \%$ & 3 \\
Non-Performance Claims & 1.54 & $38.5 \%$ & 4 \\
Different Site Conditions Claims & 1.46 & $36.5 \%$ & 5 \\
Acceleration Claims & 1.39 & $34.8 \%$ & 6 \\
Damage Claims & 1.14 & $28.5 \%$ & 7 \\
Contract Ambiguity Claims & 1.07 & $26.8 \%$ & 8 \\
\hline
\end{tabular}

\section{Causes of claims and their frequency}

The third section of the survey focused on the causes of construction claims. In this section, a table was provided with twenty six possible causes of claims. Similar to the types of claims, firms were asked to choose one of five possible options for the frequency of each cause of claims: never, rare, average, frequent, and very frequent with a weight for each in a scale from 0 to 4 . Responses for the frequency of the "Change Orders" cause of claims, for example, indicate that 5 firms did not respond, 2 responded as "never", 11 responded as "rare", 15 responded as "average", 18 responded as "frequent", and 5 responded as "very frequent". Data received from respondents were analyzed and a weighted average was calculated using equation (1) 
for each cause of claims, as shown in Table 3. For example, the average mean for the "Change Orders" cause of claims $=(0 * 2+1 * 11+2 * 15+3 * 18+4 * 5) / 56=2.05$.

Table 3: Ranking of the causes of claims

\begin{tabular}{lccc}
\hline Causes of Claims & Weighted Average & Importance Index (\%) & Rank \\
\hline Change or Variation orders & 2.05 & $51.3 \%$ & 1 \\
Delay caused by owner & 2.00 & $50.0 \%$ & 2 \\
Oral change orders by owner & 1.95 & $48.8 \%$ & 3 \\
Delay in payments by owner & 1.82 & $45.5 \%$ & 4 \\
Low price of contract due to high competition & 1.80 & $45.0 \%$ & 5 \\
Changes in material \& labor costs & 1.68 & $42.0 \%$ & 6 \\
Owner personality & 1.63 & $40.8 \%$ & 7 \\
Variations in quantities & 1.61 & $40.3 \%$ & 8 \\
Subcontracting problems & 1.57 & $39.3 \%$ & 9 \\
Delay caused by contractor & 1.55 & $38.8 \%$ & 10 \\
Contractor is not well organized & 1.55 & $38.8 \%$ & 10 \\
Contractor financial problems & 1.55 & $38.8 \%$ & 10 \\
Bad quality of contractor's work & 1.50 & $37.5 \%$ & 13 \\
Government regulations & 1.38 & $34.5 \%$ & 14 \\
Estimating errors & 1.32 & $33.0 \%$ & 15 \\
Scheduling errors & 1.32 & $33.0 \%$ & 15 \\
Design errors or omissions & 1.29 & $32.3 \%$ & 17 \\
Execution errors & 1.25 & $31.3 \%$ & 18 \\
Bad communication between parties & 1.25 & $31.3 \%$ & 18 \\
Subsurface problems & 1.21 & $30.3 \%$ & 20 \\
Specifications \& drawings inconsistencies & 1.14 & $28.5 \%$ & 21 \\
Termination of work & 1.14 & $28.5 \%$ & 21 \\
Poorly written contracts & 1.05 & $26.3 \%$ & 23 \\
Suspension of work & 1.05 & $26.3 \%$ & 23 \\
Accidents & 1.02 & $25.5 \%$ & 25 \\
Planning errors & 1.00 & $25.0 \%$ & 26 \\
\hline
\end{tabular}

An importance index percentage was then calculated using equation (2) for each cause of claims, as shown in Table 3. For example, the importance index for the "Change Orders" cause of claims $=(2.05 * 100) / 4=51.30 \%$. The results of this analysis indicate that "Change Orders" are the most frequent cause of claims. This cause of claims was ranked first with an importance index of 51.30\% while "Delay Caused by Owner" was ranked second with an importance index of 50\%. "Planning Errors" were ranked last with an importance index of $25 \%$. The ranks of all causes of claims are listed in the last column of Table 3.

\section{SETTLEMENT METHODS TO RESOLVE CLAIMS}

There are four basic settlement methods used to resolve claims in the United Arab Emirates: 1) negotiation; 2) mediation; 3) arbitration; and 4) litigation. A discussion on these four methods is shown in the following subsections.

\section{Negotiation}

Meetings between disputing parties (normally the owner's representative and the contractor) can help achieve an early resolution of a dispute. Owners tend to spend a lot of time in studying claims and any corrective action is normally postponed. If resolution is not achieved, the case passes out of the hands of those negotiating parties and goes to mediation or arbitration. 


\section{Mediation}

When negotiations fail, parties may solve their claim by having a mediator. The role of the mediator is to bring parties together. Efforts are made to reach to an agreement in order to settle the dispute. The mediator may clarify or outline the disagreements. This helps each side understand the position of the other side. Also, a mediator may make suggestions and he/she may even propose a final solution. The mediator, however, has no power to issue a final binding decision. Disputing parties are, therefore, not required to accept the mediator's decision.

\section{Arbitration}

If they do not succeed to resolve the claim using negotiation or mediation, disputing parties may use arbitration. Although, they are loath to use arbitration as a solution to resolve disputes, it might be an unavoidable resort. After an arbitrator is appointed, each party tries to convince the arbitrator of the correctness of his position and the hearing is not closed until each had a full opportunity to present his/her case. After the hearing, the arbitrator makes a final binding decision.

\section{Litigation}

If the disputing parties have not agreed on the arbitrators or if one or more arbitrators agreed upon abstaining from the job, or if there was a hindrance to proceed with it and there was no agreement between the parties in this regard, the parties may go for litigation. Although, disputing parties hate to go to courts to resolve disputes, it might be their only remaining and final resort. A judgment rendered in this matter is final and binding and may in no way be challenged.

As provided by the survey respondents, the majority of construction claims (77.2\%) are resolved using negotiation (see Fig. 3). As shown in the figure, only 5.7\% of claims were resolved using litigation. This confirms that firms in UAE are quite reluctant to go for litigation because of the long time and high costs associated with this method of dispute resolution.

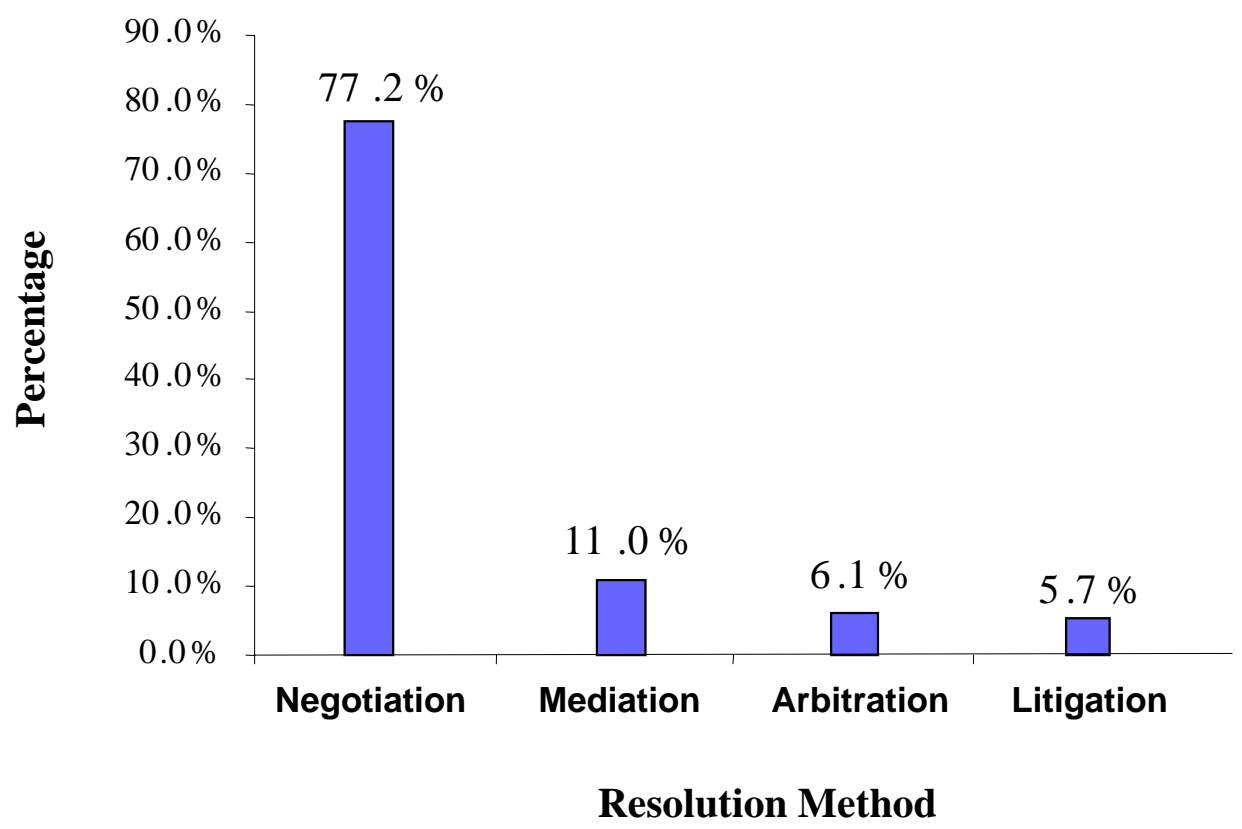

Fig. 3: Resolution methods and their percentages of use 


\section{DISCUSSION AND RECOMMENDATIONS}

With the complexity of both arbitration and litigation and with litigation time exhibition and costs continually rising, it is imperative for clients and construction firms to be able to protect themselves against construction claims. In the last part of the survey, respondents were asked to provide recommendations on how to prevent/reduce claims in construction projects and how to deal with such claims in case they happen. The following are some useful recommendations provided by the survey respondents:

- Allow reasonable time for the design team to produce clear and complete drawings, bills of quantities, and specifications with no or minimum error and discrepancies.

- Establish more efficient quality control techniques and mechanisms that can be used during the design process to minimize errors, mismatches, and discrepancies in contact documents.

- Have a third party to read contract documents before the bidding stage.

- Have a clearly written contract with no ambiguity.

- $\quad$ Read the contract several times before signing it to understand any unclear clauses.

- Use special contracting provisions and practices that have been used successfully on past projects. Useful information can be found in the ASCE booklet titled "Avoiding and Resolving Disputes during Construction: Successful Practices and Guidelines." (ASCE 1991).

- Implement constructability during the different stages of the project.

- Establish a strategy on how to deal with tighter scheduling requirements.

- Provide a proper mechanism for processing and evaluating change (variation) orders that pay for direct costs, indirect costs, and loss of productivity associated with any changes.

- Have signed change (variation) orders before starting doing these changes on site.

- Use critical path method (CPM) scheduling, cost control, and productivity analysis to monitor progress, detect any changes in productivity and/or cost, and take corrective actions in a timely manner..

- Develop cooperative, problem solving attitudes on projects, through a basic risk-sharing philosophy between the owner and the contractor.

- Maintain proper job records on a timely manner including:

- Time sheets

○ Dockets and invoices

- Diary records

- Reports

- Photographs

- Records of labor 
- Records of plant on site, and its utilization

- Weather, and its effect on progress

○ Progress of the construction

○ Instructions

- Difficulties

\section{CONCLUDING REMARKS}

The general conclusion of this study was that construction claims can be used to indicate several problem areas in the construction process. These areas should be noted and monitored by industry practitioners during all stages of the construction process. Steps should also be taken to clarify any issues or conflicts that may arise in these common problem areas. To summarize, it was found that "changes" type of claims is the most frequent type of followed by "Extra-work" type of claims. "Contract ambiguity" claims were ranked last. It can also be concluded from this study that "change orders" are the most frequent cause of claims while "delay caused by owner" was ranked second. "Planning errors" were ranked last, indicating that it is the least frequent cause of claims.

In accordance with these results, it is recommended that special consideration should be given to contract clauses dealing with change (variation) orders, disputes, variations and extra works conditions, and delay. The best means to cope with risk of construction claims is to reduce or avoid them altogether. There are certain fundamental means of reducing the number of claims encountered. The essential steps an owner can take to minimize risks and deal with the aforementioned identified causes are:

- To allow reasonable time for the design team to produce clear and complete drawings and specifications.

- To implement constructability during the different stages of the project.

- To provide a proper mechanism for processing and evaluating change orders that pay for direct costs, indirect costs, and loss of productivity associated with any changes.

- To use CPM scheduling, cost control, and productivity analysis to monitor progress and productivity.

However, there is no guarantee that claims can be avoided entirely. Avoiding claims requires understanding their causes, understanding contractual terms and obligations, and early and continued effective non adversarial communications. It is expected that the findings of this research will assist all parties to a contract to reduce liability by resolving claims through reference to contemporary records of fact and clear interpretation of contract terms. It will also help them avoid the main causes of claims and disputes and, accordingly, minimize delays and cost overruns in construction projects. The author believes the suggested comments are necessary for proper project management, which is far more advantageous and profitable than seeking advice of a construction claim consultants after the dispute is entrenched. The latter course often takes place too late and is too costly. 


\section{ACKNOWLEDGEMENT}

The author would like to thank the Research Affairs of the United Arab Emirates University for financially supporting this research. The author would also like to thank contractors, consultants, and design firms in Dubai and Abu Dhabi Emirates who participated in responding to the questionnaire survey used in this research.

\section{REFERENCES}

Abdul-Malak, M A, El-Saadi, M M and Abou-Zeid, M G (2002) Process model for administrating construction claims. Journal of Management in Engineering, 18(2), 84-94.

Al-Khalil, M and Al-Ghafly, M (1999) Important causes of delay in the public utility projects in Saudi Arabia. Construction Management and Economics, 17(5), 647-655.

ASCE Technical Committee on Contracting Practices of the Underground Technology Research Council (1991) Avoiding and resolving disputes during construction: successful practices and guidelines. ASCE, New York.

Chester, M and Hendrickson, C (2005) Cost impacts, scheduling impacts, and the claims process during construction. Journal of Construction Engineering and Management, 131(1), 102-107.

Gulezian, R and Samelian, F (2003) Baseline determination in construction labor productivity-loss claims. Journal of Management in Engineering, 19(4), 160-165.

Hartman, F and Snelgrove, P (1996) Risk allocation in lump-sum contracts - concept of latent dispute. Journal of Construction Engineering and Management, 122(3), 291-296.

Ho, S P and Liu, L Y (2004) Analytical model for analyzing construction claims and opportunistic bidding. Journal of Construction Engineering and Management, 130 (1), 94-104.

Janney, J R, Vince, C R and Madsen, J D (1996) Claims analysis from risk-retention professional liability group. Journal of Performance of Constructed Facilities, 10(3), $115-122$.

Kartam, S (1999) Generic methodology for analyzing delay claims. Journal of Construction Engineering and Management, 125 (6), 409-419.

Ren, Z, Anumba, C J and Ugwu, O O (2003) Multiagent system for construction claims negotiation. Journal of Computing in Civil Engineering, 17(3), 180-188.

Scott, S (1997) Delay claims in U.K. contracts. Journal of Construction Engineering and Management, 123 (3), 238-244.

Semple, C, Hartman F T and Jergeas, G (1994) Construction claims and disputes: causes and cost/time overruns. Journal of Construction Engineering and Management, 120(4), 785-795.

Singh, A and Sakamoto, I (2001) Multiple claims in construction law: educational case study. Journal of Professional Issues in Engineering Education and Practice, 127(3), 122129.

Vidogah, W and Ndekugri, I (1997) Improving management of claims: contractors' perspective. Journal of Management in Engineering, 13(5), 37-44. 